\title{
Storage and computation in the mental lexicon
}

\author{
R. H. Baayen ${ }^{\mathrm{a}}$
}

${ }^{a}$ Radboud University and Max Planck Institute for Psycholinguistics P.O. Box 310, 6500 AH Nijmegen, The Netherlands

\section{Introduction}

In the seventies of the previous century, the mathematical properties of formal languages have provided a key source of inspiration to morphological theory. Models such as developed by Lieber (1980) and Selkirk (1984) viewed the lexicon as a calculus, a formal system combining a repository of morphemes with rules for combining these morphological atomic units into complex words.

This approach to the lexicon was driven by two fundamental assumptions. First, the lexicon was assumed to be a compositional derivational system. Complex words were believed to be generated from simpler forms (Bloch, 1947; Chomsky and Halle, 1968). Second, following Bloomfield (1933), the set of atomic elements was assumed to comprise any word or formative that is not predictable by rule. Rule-governed combinations of these atomic units, the regular complex words, were assumed not to be available as units in the lexicon, as storage would introduce unnecessary redundancy in the model. Instead of being listed (i.e., stored without analysis or substructure), regular complex words were generated (produced or parsed) by rule. Unsurprisingly, the goal of morphological theory was seen as accounting for which words belong to the set of possible words in the languages of the world. The question of whether a regular complex word exists in a language was regarded as a question addressing performance rather than competence, and hence irrelevant for morphological theory.

Although many other formalisms have been developed to replace sequences of rules (Halle and Marantz, 1993; McCarthy and Prince, 1993), these formalisms did not challenge these fundamental assumptions of generative morphology. In optimality theory, for instance, forms still enter into derivational relations, even though the algorithm that relates underlying forms to surface forms is not based on a sequence of rules but on constraint satisfaction.

This type of theory of the lexicon is to a surprising extent equally adequate as a competence theory for how a pocket calculator works. A pocket calculator has a set of atomic elements, the symbols on its keys. Its chip is endowed with a small set of arithmetic rules that, when supplied with a legal string, compositionally evaluate this string. Whenever a pocket calculator is requested to evaluate a string such as ' $2+3$ ', it computes the outcome. It has no memory that holds the output of previous evaluations of the same string. It never learns from past experience. The balance of storage and computation is shifted totally to the maximization of computation and the minimization of storage. 
A first goal of this chapter is to show that the pocket calculator provides a fundamentally flawed metaphor for understanding morphological structure and processing in the mental lexicon. To this end, we first survey evidence from experimental studies of lexical processing, and then consider another source of information, the fine phonetic detail that is present in the acoustic signal. We then address the second goal of this chapter, to provide an indication of the kind of formal mathematical model that may help us to better understand process and representation in the mental lexicon.

\section{Experimental evidence}

Over the last twenty-five years, the regular and irregular past tense forms in English and related languages have provided a rich testing ground for theories of morphological processing. Whereas English regular verbs have a past tense form in the dental suffix -ed (e.g., walked, claimed), irregular verbs have past tense forms that range from suppletion (go/went) to invariance (cut/cut) and from pure vocalic alternation (give/gave) to combinations of vocalic alternation and a variant of the dental suffix (sell/sold). Bybee and Slobin (1982) and Bybee and Moder (1983) called attention to the many kinds of subregularities that characterize the irregular verbs, which older structuralists had already characterized as semi-productive (e.g. Van Haeringen, 1940).

Most researchers understand regular past tense forms as being derived from their present tense stems (Bloch, 1947; Chomsky and Halle, 1968) by a simple rule adding the dental suffix. Although irregular past tense forms might also be analysed as governed by various unproductive rules, such rule-based descriptions tend to be baroque, fairly arbitrary and uninsightful. For understanding the semi-regularities of the irregular past tense, connectionist models offered an alternative that obviated the need for a series of ad hoc unproductive rules (Rumelhart and McClelland, 1986; McClelland and Patterson, 2002b). The response of generative linguists (Pinker and Prince, 1988, 1994; Pinker, 1991) was to defend the Bloomfieldian model by claiming that regular and irregular morphology belong to two completely independent cognitive systems, the dual mechanisms of rule (for regulars) and rote (for irregulars). Irregulars would be stored in an associative memory, regulars would not be stored at all but always derived by means of morphological rules (Pinker, 1991, 1997).

The theory of speech production developed by Levelt et al. (1999) and its computational implementation in the WEAVER model (Roelofs, 1996, 1997a,b) provide a psycholinguistic formalization of the generative approach to storage and computation. The WEAVER model embodies a fully decompositional theory of morphological processing in production. Conceptual representation for words like handbooks and walked are linked to lemma representations, which specify their syntactic and inflectional properties (handbooks is a plural noun, walked a verb in the past tense). These lemma representations activate the form representations (lexemes) of their constituent morphemes, hand, book and $s$ for handbooks, and walk and -ed for walked. In this model, complex words do not receive their own lexemes, they are assumed always to be produced through their constituents. In the absence of immediate constituents, irregular verbs are assigned their own lexemes. In short, the WEAVER model, as well as the general approach of Pinker and colleagues, take as their point of departure that morphology is a simple formal system similar in essence 
to the computational system implemented in a standard pocket calculator.

Although a model like WEAVER is attractive for its simplicity, economy, and the broad range of experimental data that it accounts for, it is becoming increasingly clear that its generative design leads to a series of subtle predictions that turn out to be demonstrably incorrect.

\subsection{Storage is ubiquitous}

First, storage is not restricted to irregular words. Fully regular complex words also leave traces in lexical memory, as shown by Taft (1979) and Sereno and Jongman (1997) for comprehension in English, Baayen et al. (1997, 2002) for comprehension in Dutch, and Bien et al. (2005) for production in Dutch. All these studies observed that the frequency of a complex word itself was predictive for processing latencies, independently of the frequencies of its constituents. Such a frequency effect is widely regarded as a proof of existence of a separate independent representation for a complex word. It has been argued that in English regular complex words would not leave traces in lexical memory when their frequencies fall below a threshold of 6 per million (Alegre and Gordon, 1999). However, Wurm and Baayen (2006) observed a word frequency effect for English regular inflected words well below this threshold in both visual and auditory lexical decision.

Interestingly, the presence of a word frequency effect went hand in hand with the absence of a stem frequency effect in the data of Wurm and colleagues. Traditionally, word frequency and stem (or root) frequency effects have been interpreted as the hallmarks of whole word based processing versus decompositional processing respectively. For very low-frequency words, however, it is highly unlikely that morphological structure is completely irrelevant. Therefore, Wurm and colleagues suggest that word frequency be reinterpreted as a joint probability, the probability of the co-occurrence of the immediate constituents. If this interpretation is correct, lexical frequency effects may derive from two sources: memory for phonological sequences (morphs), and memory for sequences of such sequences, i.e., sequences of morphs. For (regular) complex words, both kinds of memory are probably involved simultaneously.

In more recent work, Pinker and colleagues acknowledge that regulars can be stored. Nevertheless, their argument is that regulars may perhaps be stored, but crucially they need not be stored. In normal language use, regulars would be processed by rule, and only under extreme experimental conditions would one begin to see that regulars have their own, albeit normally superfluous, representations (Pinker and Ullman, 2002a,b).

However, why would supposedly redundant storage of regulars take place at all? In fact, we can infer from its mere existence in experiments that it must be advantageous for the brain to keep track of detailed combinatorial probabilities, contrary to what the metaphor of the pocket calculator would lead one to expect. Interestingly, De Vaan et al. (2007) discuss preliminary evidence that regular complex forms may already leave a trace in memory after just a single exposure. Crucially, their evidence is not restricted to visual lexical decision, but extends to self-paced reading, a task with a much higher degree of ecological validity.

One of the advantages that storage offers for lexical processing is probability-driven elimination of unlikely but possible segmentations in comprehension. Spurious segmentations are ubiquitous not only in syntax but also in morphology, and knowledge about the 
likelihood of substructures is crucial for efficient selection of the most likely morphological parse (Baayen and Schreuder, 2000; Bod, 2006).

\subsection{Processing is not derivational}

Given that regular inflected words seem to have their own traces in memory, it is no longer necessary to assume that a past tense form is derived from its stem. The idea that complex forms are, in some real sense, constructed on-line from their parts, i.e., that a past-tense form like walked is derived in real time from its stem walk, is one of the few assumptions that many connectionist models (Rumelhart and McClelland, 1986; Plunkett and Marchman, 1991; MacWhinney and Leinbach, 1991) share with symbolic theories. Evidence is accumulating, however, that this very common assumption is wrong.

One source of evidence stems from research on speech errors. Stemberger and Middleton (2003) presented irregular verbs in the progressive form (is falling), and asked subjects to respond with the simple past $(f e l l)$. When the vowel of the past tense is more frequent in the language in general compared to the vowel of the present tense, overregularisation errors (falled for fell) decreased. When it is less frequent, overtensing errors (felled for fall) were more likely. These data suggest that the present and past tense forms are in competition, and that this competition is modulated by the a-priori probabilities of the vowels in these verb forms (see also Stemberger 2004).

Tabak et al. (2005b) obtained further evidence for competition between the past and present tense forms using a task in which subjects were shown a present or a past tense form, and were asked to say out loud the corresponding past or present tense form. In this task, henceforth cross-tense naming, the ratio of the frequency of the form seen to that of the form said was inhibitory. This inhibitory effect was the same for both irregular and regular verbs. It also did not vary with the direction of naming, from present to past or from past to present. In cross-tense naming, the form seen (the cue) apparently inhibits the form to be said (the target). The presence of this effect for irregulars is expected in the light of the results of Stemberger and Middleton (2003). Its presence also for regulars shows that the present and past tense forms of regulars exist in the mental lexicon just as the present and past tense forms of irregulars. Interestingly, the ratio of the two inflectional variants was not predictive at all in straightforward word naming nor in picture naming of the same forms. This shows that in normal situations, the two inflectional variants are not considered jointly, which would be necessary if one form is to be derived from the other. Instead, the targeted form is retrieved from memory without noticeable interference from its counterpart in the opposite tense.

\subsection{Paradigmatic structure affects processing}

We have seen that probabilistic information about individual inflectional variants is available in lexical memory. It is well-known that inflectional variants are organized in paradigms (see, e.g., Matthews, 1974). From the syntagmatic perspective of standard decompositional approaches, paradigms are enigmatic oddities with little more status than educationally useful ways of displaying inflectional variants. After all, to the extent that an inflectional variant is decomposable, its structure can be accounted for by a syntagmatic rule. However, paradigmatic structure and its complexity is emerging from recent experimental studies as a genuine independent factor in lexical processing. 
Moscoso del Prado Martín et al. (2004b) developed, as part of an overall informationtheoretic measure of processing complexity, a measure of paradigmatic inflectional complexity based on the entropy measure of Shannon and Weaver (1949),

$H=-\sum_{i} p_{i} \log _{2}\left(p_{i}\right)$

where $i$ ranges over inflectional variants, and $p_{i}$ is the probability of a variant in its paradigm (estimated by its relative frequency in the paradigm). Baayen et al. (2006) considered this measure (henceforth inflectional entropy) by itself in a regression study of English monomorphemic words, applying (1) in its simplest form by allowing $i$ to range over all inflectional variants of a given word. They observed a negative correlation of inflectional entropy with response latencies in visual lexical decision, and a positive correlation for subjective frequency estimates. Words with a more complex, informationally rich inflectional paradigm have more connections to other words in the mental lexicon, and this superior lexicality allows faster lexical decision responses and gives rise to higher subjective frequency estimates. Tabak et al. (2005a) also observed a (non-linear) effect of inflectional entropy for Dutch verbs in visual lexical decision.

The information structure of more complex paradigms has also been shown to affect morphological processing. Kostić et al. (2003) investigated Serbian nominal paradigms with visual lexical decision. Their key predictor was the average probability of a syntactic function of a given case inflection expressed in bits of information. This information measure can be calculated across all relevant nouns in the language, or it can be calculated for each noun separately. For instance, Serbian plural feminine nouns take the ending -ama for the dative and the instrumental. We can base our estimate of a syntactic function such as recipient either across all feminine plurals, or for a specific noun, say ženama. Kostic and colleagues observed that both the general and the item-specific measures were predictive, with forms carrying a higher information load giving rise to prolonged response latencies.

Current work on Dutch and Spanish using the picture naming paradigm suggests that inflectional structure is also predictive for speech production. Tabak et al. (2006) observed a facilitatory effect for inflectional entropy for Dutch past-tense forms, for both regular and irregular verbs. For Spanish verbs, (Van Buren et al., 2006) observed facilitation for the inflectional family size, i.e., for the number of nonzero inflectional variants realized in a corpus, over and above an effect of the word's lemma frequency. Note that the effects of inflectional entropy and the inflectional family size bear further witness, albeit indirectly, to the presence of memory traces for regular inflected words.

Paradigmatic effects in morphological processing are not restricted to inflection. The derived words and compounds in which a word occurs, its morphological family, codetermines lexical processing (Moscoso del Prado Martín et al., 2004a). Furthermore, morphological family members sharing the same structural position have been found to constitute a domain of analogical generalisation (Krott et al., 2001). Analogical generalization challenges the high level of abstraction that is part and parcel of classical syntagmatic approaches — a syntagmatic rule by definition is blind to the properties of individual words and has access only to a selection of abstract general features. Not surprisingly, the syntagmatic design of decompositional models renders them unable to 
account for the many analogical, graded effects in morphology and morphological processing (Seidenberg and Gonnerman, 2000; Ernestus and Baayen, 2003; McClelland and Patterson, 2002b). Importantly, whereas (Pinker, 1997) assumed that analogical similarity would be restricted to irregulars, as irregulars and only irregulars would be stored in an associative memory, Albright and Hayes (2003) have shown that regulars are also subject to analogical similarity (islands of reliability in their terminology) just as are irregulars (see also Ernestus and Baayen 2003).

\subsection{Form and meaning interact}

The decompositional approach of Levelt et al. (1999) implements a high degree of modularity and encapsulation. Conceptualisation leads to the selection of a lemma. Once a lemma has been selected, a new process activating the relevant constituent morphemes is started up. This process is completely independent of prior conceptualization processes. Once a morpheme (lexeme) has been activated, it in turn activates its constituent phonemes, again fully independently of any preceding processes. The hypothesis underlying encapsulated modeling is that the rules and regularities at the level of word form operate independently from rules and regularities at the level of word meaning. Thus, Pinker regards semantics as irrelevant for the past tense (Pinker, 1999).

In connectionist approaches to morphology, the modularity assumption is dropped, and form and meaning are allowed to interact, as for instance in the triangle model (Joanisse and Seidenberg, 1999; Seidenberg and Gonnerman, 2000). Patterson et al. (2001a,b) argue that irregulars come to depend more on semantic similarity compared to regulars due to reduced similarity in their phonological form. They call attention to the cooccurrence of semantic deficits with degraded performance on irregular verbs (but see Tyler et al. 2004).

Furthermore, there is independent distributional evidence that irregular verbs tend to have more semantic neighbors than do regular verbs (Baayen and Moscoso del Prado Martín, 2005). Experimental evidence that this difference in semantic density between regulars and irregulars may affect lexical processing is reported by Tabak et al. (2005a). They observed that in visual lexical decision, semantic density (gauged by means of the count of synonym sets in WordNet) was more facilitatory for irregular past tense forms than for regular past tense forms. It is precisely the forms of irregular verbs that carry the irregularity for which we find that the greater semantic density of irregulars verbs boosts lexical processing.

Differences in embodiment (Barsalou, 2003; Feldman, 2006) may also be involved. Table 1 lists a number of basic verbs for position and movement in English and Dutch. In both languages, irregular verbs are in the majority, suggesting that irregular verbs have a greater degree of embodiment than regulars. Work in progress (Tabak et al., 2006) provides further evidence for this hypothesis. We had artists make photographs of verbal actions, covering some 180 verbs. The artists who made the photographs of verbal actions reported that acting out irregulars was much easier than acting out regulars. This subjective impression was supported by two observations. First, the byte size of the jpeg files of photographs for irregulars were significantly smaller than those for regulars. Second, if we look at the names elicited from subjects for the pictures, we see that the uncertainty about the pictures' names (measured by means of entropies over the frequency distribution of different verbs elicited for a given picture) was much smaller for irregu- 
lars than for regulars. Possibly, the greater degree of embodiment of irregular verbs, in combination with their greater semantic density, may not only render them more easy to understand and conceptualize, but may also contribute to their remarkable resistance against regularization.

Table 1

Basic verbs for position and motion in English and Dutch. Irregular verbs are shown in upper case, regular verbs in lower case.

verbs of position

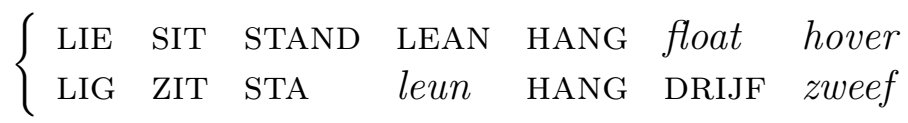

verbs of motion

\begin{tabular}{|c|c|c|c|c|c|}
\hline $\begin{array}{l}\text { walk } \\
\text { LOOP }\end{array}$ & $\begin{array}{l}\text { crawl } \\
\text { KRUIP }\end{array}$ & $\begin{array}{l}\text { jump } \\
\text { SPRING }\end{array}$ & $\begin{array}{l}\text { RUN } \\
\text { ren }\end{array}$ & $\begin{array}{l}\text { SWIM } \\
\text { ZWEM }\end{array}$ & $\begin{array}{l}\text { SINK } \\
\text { ZINK }\end{array}$ \\
\hline RIDE & FLY & climb & ascend & descend & FALL \\
\hline RIJD & VLIEG & KLIM & STIJG & daal & VAL \\
\hline
\end{tabular}

We have seen that storage is ubiquitous and not restricted to regulars, that morphological processing is not derivational in the sense that more complex forms are derived on-line from less complex forms, that the paradigmatic relations between complex words across inflection and word formation co-determine lexical processing and generalization, and that form and meaning interact. All these observations run counter to the predictions of fully decompositional generative models.

\section{Phonetic evidence}

The evidence considered thus far was gathered from domains that traditionally are at the heart of psycholinguistic investigation. In this section, we consider the consequences of morphological structure for the fine phonetic detail of complex words. Evidence is accumulating that the speech signal itself constitutes an additional source of information about the architecture of the mental lexicon.

\subsection{Lexical competition and the computation of fine phonetic detail}

According to the model of Levelt et al. (1999), the process of word form encoding is initiated once a word's lexeme has been activated. The lexeme sequentially activates the word's phonemes from first to last. Phonemes are grouped into syllables, and syllables are looked up in a syllabary, which provides gestural scores driving articulation.

The WEAVER model implements key insights of mainstream generative phonology. It embodies an important intuition, an axiom driving its design, namely, that once we know 
which word we need for expressing a given concept, we can select the form of that word without interference from the forms of other irrelevant words. In WEAVER, this intuition is formalized by the restrictions that the only way a lexeme can be activated is through its own lemma, and that only the lemma selected from the set of candidate lemmas will activate its lexeme. As a consequence, lexemes are viewed as highly encapsulated representations that would not enter into competition with each other.

Studies investigating speech errors (e.g., Sevald et al., 1995; Dell et al., 1999) have long suggested that word forms enter into a process of lexical competition during speech production. More recently, advances in laboratory phonology and phonetics have provided further evidence for lexical competition during word form encoding. Recall that in auditory comprehension, the cohort of a word's lexical competitors is gradually reduced as acoustic information unfolds over time (Marslen-Wilson, 1996; Marslen-Wilson and Welsh, 1978). Several phonetic studies provide evidence that a similar competition process characterizes speech production.

Van Son and Pols (2003) observed that the fine phonetic detail of a given segment in the word reflects the information load of that segment. In their study of Dutch, segments that contributed more to reducing the cohort were pronounced with longer acoustic durations and with increased articulatory effort, quantified by means of the spectral center of gravity (see also Van Son and Van Santen, 2005).

The measure that Van Son and Pols used for gauging a segment's information load, $I_{L}$, is the negative log to base 2 of a ratio of two probabilities. The first probability, $p_{+}$, estimates the joint probability (by means of token counts) of all words that begin with the same sequence of segments up to and including the target segment. For the [I] in sit, all words beginning with $[\mathrm{sI}]$ are taken into account. The second probability, $p_{-}$, estimates, again by means of token counts, the joint probability of all words beginning with the same sequence of segments up to but not including the target segment. For [I] in sit, this second probability considers all words that begin with $[\mathrm{s}]$. Thus, a segment's information load is defined as

$I_{L}=-\log _{2} \frac{p_{+}}{p_{-}}$

What makes $I_{L}$ interesting is that it gauges the extent to which the [I] in sit contributes to reducing the uncertainty in the cohort. Before the $[\mathrm{I}]$ is considered, the amount of information in the cohort is $-\log \left(p_{-}\right)$(Shannon and Weaver, 1949). Once the $[\mathrm{I}]$ is considered, however, the amount of information in the cohort increases to $-\log \left(p_{+}\right)$. Since $-\log (a / b)=\log (b)-\log (a)$, it is easy to see that $I_{L}$ quantifies the extent to which the set of competitors before the [I] comes in (characterized by the larger and hence less information rich joint probability $p_{-}$) is reduced by the $[\mathrm{I}]$ (resulting in the smaller more informative joint probability $\left.p_{+}\right)$.

Van Son and Pols (2003) actually used a more complex estimate of $I_{L}$ that was weighted for the contextual likelihood of the word containing the target segment, i.e., the word for which duration and spectral center of gravity were measured (sit). However, how to optimally estimate the cohort probabilities $p_{+}$and $p_{-}$requires further research. For instance, Kuperman et al. (2006), following up on Van Son and Pols (2003), observed improved correlations when estimating $p_{+}$and $p_{-}$not with token-based counts but instead with type counts. Furthermore, this study investigated the predictivity of $I_{L}$ as defined 
in (2) for the divergence of phonemes from their mean durations, rather than the raw durations of these phonemes. Although the two studies are not directly comparable, their results are consistent: It is clear that a segment with greater lexical information tends to have a longer duration. Furthermore, the acoustic signal as produced by the speaker is advantageous for the listener, as segments which are more important for distinguishing the target word from its competitors in the auditory cohort are more prominently present in the speech signal.

This finding raises the question of whether the speaker is modulating the fine phonetic detail of a word's segments explicitly with the purpose of facilitating comprehension for the listener, in line with Lindblom's hypo- and hyper-articulation theory (Lindblom, 1990). Although it makes sense to assume that the communicative efficiency of speech is enhanced by the hyperacticulation of informationally more salient segments and the hypoarticulation of informationaly more redundant segments (Aylett and Turk, 2004; Van Son and Van Santen, 2005), it seems unlikely that this efficiency is due to some conscious or even unconscious effort on the part of the speaker to accomodate to the listener. Speakers can adjust their speech depending on their audience, the acoustics of their environment, whether or not they are using a telephone, etc. But purposeful modulation of phonetic detail at the fine-grained level that is at issue here seems highly unlikely. For instance, Bard et al. (2000) observed that clarity of spontaneous speech was predictable from the speaker's knowledge, and not from the listener's knowledge. Furthermore, Kuperman et al. (2006) observed the effect of informational redundancy on the details of acoustic durations within a single register, read aloud speech from the library for the blind as available in the spoken Dutch corpus. Although the speakers sampled in this corpus produced carefully articulated speech modulated to fit the needs of their intended audience, informational redundancy still emerges as an independent predictor for phonetic detail within this register. Trón (2006) likewise points out that it is unlikely that the modulation of acoustic duration by previous mentions of a word in the discourse involves adaptation of the speaker to the needs of the listener.

Although it is logically possible that speakers purposefully adjust to their listeners, it is logically equally possible that fine phonetic detail is the straightforward consequence of the organization of the mental lexicon. Instead of repeating traditional explanations based on the interaction between speaker and listener, we therefore explore the viability of explanations based on what we know about lexical access.

We know from research on auditory word recognition that the incoming speech signal is matched incrementally against a pool of lexical candidates that is winnowed down as more acoustic information becomes available. According to the theory of Levelt et al. (1999), word form encoding in speech production would require a fundamentally different architecture, with word form selection being driven by semantics, and proceeding without lexical competition. However, consider the possibility that word form encoding in production makes use of the same phonological memory that is addressed in auditory comprehension, and that accessing this phonological memory always involves a probabilistic process of lexical competition during which the target word is singled out from its phonological neighbors.

In comprehension, the greater amount of fine phonetic detail in the acoustic signal (in the sense of a strengthened articulatory realization) that is present for more discriminative 
segments allows the listener to distinguish the carrier words of these segments more rapidly and reliably from their lexical competitors. In production, by contrast, the speaker has to retrieve a representation from phonological memory. During this retrieval process, lexical competitors are co-activated. The co-activation of these competitors seems to come with two benefits. First, as suggested by naming experiments reported by Vitevitch (2002), phonological neighbors appear to gang up to facilitate production in a morphologically simple language like English (but see Vitevitch and Stamer (2006) for the opposite effect in a morphologically rich language, Spanish).

Second, a greater neighborhood density also has been observed to correlate in English with strengthened phonetic detail. Wright (2004) and Munson and Solomon (2004) reported that words with a high frequency and low neighborhood density (easy words) were articulated with more centralized vowels than words with a low frequency and a high neighborhood density (hard words). Scarborough (2004) observed that words with a low frequency and a high neighborhood density were characterized by higher degrees of coarticulation. One type of coarticulation that she studied was nasal coarticulation, which concerns the extent to which the vowel in a word like band is nasalized in anticipation of the following nasal. Scarborough also measured vowel-to-vowel coarticulation, i.e., the extent to which the first (or second) vowel affects the location in $F_{1}--F_{2}$ acoustic space of the second (or first) vowel. What she found was that more coarticulation takes place for words with more neighbors. Apparently, once in the course of lexical competition the phonetic characteristics of a segment have been highly activated, these characteristics are not easily de-activated and may spill over to neighboring segments with which they are compatible. Interestingly, the effect of neighborhood density on coarticulation also emerged in Scarborough's experiments for nonwords. This indicates that these effects do not hinge on phonetically rich stored representations, but emerge during lexical competition.

These studies suggest that hyperarticulation is part and parcel of increased lexical competition. The more intense the process of lexical competition is, the more the unique properties of a word become relevant for distinguishing it from its competitors. As a consequence, greater lexical competition results in superior and more detailed lexical activation. In short, the corrollary of inceased competition is greater articulatory precision.

The results obtained by Van Son and Pols (2003) and Kuperman et al. (2006) add a temporal perspective to the consequences of neighborhood structure for articulation reported by Wright (2004) and Munson and Solomon (2004). Standard definitions of a word's neighbors are string-based, and consider those words as competitors that differ with respect to a single segment, unweighted for its position in the string. The measure of lexical information studied by Van Son and Pols, by contrast, taps into the temporal dynamics of lexical competition by gauging the extent to which a given segment succeeds in disqualifying irrelevant competitors that up till then were viable alternatives. Further evidence for sequentiality in speech production is provided by Sevald and Dell (1994), who observed slowed production for sequences of words with discrepant initial segments (initial neighbors) compared to words with discrepant final segments (final neighbors). Their results suggest that the position of the segment that is exchanged to obtain a neighbor is crucial for understanding word form encoding in speech production. (For discussion of the vulnarability of initial segments against the backdrop of the phenomenon of prosodic 
strengthening, see Keating (2006).)

Further evidence for the relevance of the position at which words differ from their neighbors, i.e., the position at which the competition is focussed, pertains to morphologically complex words. Bien et al. (2006) calculated separate counts of the numbers of neighbors at the initial, the second, and the third position of the stems of derived and inflected words. In parallel, Bien also considered the entropy of the relative frequencies of the cohort of lexical competitors at these three positions. She studied these predictors in a position-response association task (cf. Cholin et al., 2004; Bien et al., 2005), a naming task that seeks to minimize the effect of comprehension processes in production experiments. Bien observed an inhibitory effect of the neighborhood count for the initial position, and a facilitatory effect of the cohort entropy at the second position. Her results confirm that lexical competition at the initial position slows word form encoding, and add the new finding that lexical competition at the second position facilitates word form encoding. Tabak et al. (2006) observed a similar pattern of results with the standard word naming paradigm, using monomorphemic Dutch verbs. Again the positional neighborhood count at the initial position of the word was inhibitory, whereas the positional count at the second position, and also the summed count of neighbors for later positions in the word, were both facilitatory.

The inhibition observed in naming latencies for initial neighbors is consistent with the results reported by Sevald and Dell (1994) for rapid sequence naming. The facilitation at later positions may be the driving factor behind the facilitation reported by Vitevitch (2002) for a non-positional neighborhood count. Assuming that these results are robust and replicable, the hypothesis suggests itself that positional densities might be predictive for the duration with which the corresponding target segments are produced. Preliminary results suggest that indeed a greater density at the initial phoneme gives rise to prolonged acoustic duration of this phoneme.

In summary, rich phonetic detail seems to be the by-product, or perhaps even the goal, of lexical competition in speech production. Assuming that replication studies will consolidate these findings, we may speculate that a word's phonological form is not a static representation (as a string in computer memory) nor a simple piece of code that sequentially triggers the activation of an otherwise static sequence of segments, as in the WEAVER model. Instead, a word's phonological form may be the outcome of a dynamic competition process that is biased either by acoustic input (in comprehension) or by meaning (in production). In other words, the morphs that from a morphologist's perspective seem to be the basic units stored in memory are themselves the resultant of a dynamic selection process.

\subsection{Syllabification and fine phonetic detail}

Syllabification is a well-studied phonological process that affects morphologically complex words, where it may assign stem-final consonants to the onset of a new syllable containing a vowel-initial affix as rime. The ensuing changes in fine phonetic detail have surprising consequences for the listener.

When the comparative suffix -er is added to an adjectival base, our orthographic conventions suggest that the comparative form is simply a longer continuation of the adjectival base, and that morphological information becomes available to the listener once the first 
phoneme of the suffix has been heard. However, syllabification of warmer as war-mer has far-reaching consequences for the fine phonetic detail of the stem (Lehiste, 1972). Kemps et al. (2005a) and Kemps et al. (2005b) showed that listeners are highly sensitive to the durational differences between a base word by itself (warm) and the base word as it occurs in an inflected or derived word (warmer). In a word like warmer, the vowel and the coda of warm tend to be articulated with shorter durations than when warm is a word by itself. Even though there are tremendous differences in speech rate both between and within speakers, listeners nevertheless have been found to be highly sensitive to these durational differences. For instance, when the Dutch singular kant ('side') is spliced out of its plural kanten and presented to Dutch listeners in a number decision task, response latencies to the spliced-out singular were longer than for normal singulars. Moreover, the shorter the spliced-out singular was compared to its normal counterpart, the longer response latencies were found to be. This prosodic mismatch effect was observed both for words and (phonotactically legal) pseudowords, which shows that we are dealing with general inferential processes that are not driven primarily by word-specific articulatory information in memory.

A key challenge in this line of research is to establish whether these findings generalize from laboratory speech to spontaneous conversational speech. The mere fact that listeners are able to make use of these subtle cues already suggests that they must be functional as well in normal language use. Work reviewed by Hawkins (2003) points in the same direction.

\subsection{Morphological effects on fine phonetic detail}

Fine phonetic detail is predictable not only from the dynamics of lexical competition and from general syllabification processes, but also from a word's morphological properties. We first consider syntagmatic properties, and then discuss paradigmatic properties.

According to Levelt et al. (1999), the word frequency effect arises at the level of the lexeme. The higher the frequency of a morpheme is, the faster its lexeme is assumed to initiate activation of its phonemes. This model predicts that frequency effects for complex words do not arise. We have already reviewed ample chronometric evidence that falsifies this prediction. Further evidence arguing against this decompositional approach to speech production is provided by a detailed examination of the fine phonetic detail of complex words.

Pluymaekers et al. (2005b) studied the acoustic durations of four Dutch derivational affixes in spontaneous conversations. For three out of four affixes, Pluymaekers documented that the acoustic duration of the derivational affix tended to decrease with increasing word frequency. In a laboratory study eliciting complex words with these same derivational affixes across three speech rates, Pluymaekers et al. (2006) observed the very same negative correlation between frequency and acoustic duration, which now was robust for all four affixes studied. These results, which are in line with the data reported by Jurafsky et al. (2001) for monomorphemic words, show that stored word-specific information co-determines a word's acoustic realization.

That the amount of effort invested in articulation is inversely related to the frequency of the complex words has also been demonstrated for assimilation in compounds by Ernestus et al. (2006). Higher-frequency compounds tended to undergo more assimilation at the 
constituent boundary (e.g., $t d$ in wet + boek, 'law book', assimilating to $d b$ ) than lowfrequency compounds.

Paradigmatic relations have also been shown to be predictive for fine phonetic detail. Hay (2001) observed that t-deletion in words like swiftly is more likely than in words like softly. The likelihood of deletion turns out to be positively correlated with the ratio of the frequency of the complex word to that of its base. The greater the extent to which the complex word is independent of its stem, the lesser the functionality of the low-probability diphone $t l$ becomes for morphological segmentation, and hence the greater the likelihood that this cluster can be simplified without loss of comprehension.

A second example of the reflection of paradigmatic structure in fine phonetic detail concerns the duration of the interfix in Dutch compounds. Krott et al. (2001) showed that the probability distribution of the interfixes in the set of compounds sharing the left immediate constituent is crucial for understanding the otherwise enigmatic selection of the interfix in Dutch novel and existing (Krott et al., 2004) compounds. The greater the likelihood of a given interfix in this probability distribution (henceforth its bias), the greater the likelihood is that it is used, and the shorter its required processing time. Kuperman et al. (2006) measured the acoustic duration of the interfixes - $s$ and -en in the spoken Dutch corpus (Oostdijk, 2002; Oostdijk et al., 2002), using the read aloud speech from the subcorpus 'library of the blind'. Kuperman considered many other variables along with this paradigmatic bias in the statistical analysis. One of these control variables was the abovementioned $I_{L}$ measure of Van Son and Pols (2003), which showed that if the interfix conveyed more information with respect to its acoustic cohort, it was realized with longer durations. Interestingly, Kuperman observed that independently of the other predictors and independently of the $I_{L}$ measure, interfixes with a greater bias were pronounced with greater acoustic durations. Apparently, a greater bias is not a measure of greater informational redundancy, but a measure of the amount of paradigmatic support for an interfix: Interfixes with greater paradigmatic support are articulated more robustly.

A final example of the consequences of paradigmatic structure for morphological processing, but now for comprehension, concerns the phenomenon known as final devoicing in Dutch. For a subset of Dutch stems ending in an obstruent, this obstruent alternates between voiceless (when syllable-final) and voiced (when syllable-initial), compare raaf ('raven'), plural ra-ven. Ernestus and Baayen (2006b) calculated the probability in a word's inflectional and derivational paradigms that its obstruent is voiced, its paradigmatic likelihood of voicing. They presented word forms in which the final obstruent is voiceless or nearly voiceless in an auditory lexical decision experiment. Words with a high paradigmatic likelihood of voicing, i.e., words that are predominantly used with inflectional forms that have the obstruent voiced, elicited longer reaction times. This shows that the distribution of voicing within the paradigm codetermines the listener's expectations. When these expectations are violated, responses are slowed. Interestingly, forms realized with residual voicing elicited longer latencies than words with completely voiceless final obstruents. The fine phonetic detail of residual voicing in the acoustic signal (which itself probably arises due to phonological paradigmatic analogy, Ernestus and Baayen 2003, 2006a) is detected by the listener, and decreases the listener's estimate that a voiceless variant is being heard. As a consequence, the response to the voiceless variant is slowed.

We have seen that lexical competition among monomorphemic words gives rise to en- 
hanced articulatory detail. This suggests that a word's canonical form is dynamically computed during lexical competition process, and that this competition process causes a word's phonetic form to be optimally distinct from its nearest phonological and morphological neighbors. Dynamic computation likewise takes place at the paradigmatic level, across sets of morphological neighbors instead of across sets of phonological neighbors. For both monomorphemic and complex words, computations are involved that crucially involve a word's own specific neighbors. Since decompositional models only have abstract rules expressing global syntagmatic generalizations across the lexicon at their disposal, they are severely challenged by what is now known about the consequences of phonological and morphological neighborhoods for the articulation of fine phonetic detail.

In addition to dynamic computation, word-specific biases for phonetic detail may be at work. Jurafsky et al. (2002) argue that English of is realized differently in the Switchboard corpus according to whether it expresses the genitive, the partitive, or a complement. Kemps et al. (2005b) discuss the possibility that the odds of encountering the base versus a bisyllabic derivative may further help listeners to optimize their responses in the number decision task. Gahl (2006) reports evidence that homophones such as thyme and time differ systematically in duration, with the more intensively used alternative receiving, on average, the shorter acoustic realization.

Especially with respect to extremely reduced words, word-specific variation can be quite extensive. Dutch natuurlijk ('nature-like', i.e., 'of course'), for instance, is attested with reduced forms ranging from ntuurlijk, tuurlijk, ntuuk, tuuk to tk (Ernestus, 2000). The choice of a given reduced form depends in part on the syntactic and discourse context (Plug, 2005), and in part on social and geographical variables. Keune et al. (2005) document, for instance, that severe reduction in colloquial Dutch of high-frequency words such as natuurlijk and eigenlijk ('own-like', i.e., 'actually') to tuuk and eigk is more common in the Netherlands than in Flanders.

The syntagmatic and paradigmatic lexical forces affecting the fine phonetic detail of a word are themselves part of a larger set of forces that co-determine the details of articulation, such as the probability of a word given the preceding or following word (Bell et al., 2003; Gregory et al., 1999; Jurafsky et al., 2001), the probability of the syntactic construction in which a word is used (Gahl and Garnsey, 2004, 2006), and the recency with which a word has been heard in (conversational) discourse (Fowler and Housum, 1987; Fowler, 1988; Hawkins and Warren, 1994; Bard et al., 2000; Pluymaekers et al., 2005a; Trón, 2006). From this overall perspective, it seems that fine phonetic detail at lexical and sublexical levels realizes a kind of informational prosody that reflects probabilistic generalizations at all levels of linguistic structure, complementary to (or possibly subsuming) classical prosodic structure and its consequences for articulatory realization (see, e.g., Keating, 2006)).

\section{Towards a new class of theories}

The results reviewed in the previous sections show that the mathematics of formal languages do not provide an adequate metaphor for understanding the mental lexicon. One of the key issues for current research is what kind of formal frameworks might then be worth pursuing instead. 
An alternative approach that has been studied intensively but with hotly debated success is connectionist modeling (e.g., Rumelhart and McClelland, 1986; Seidenberg and Gonnerman, 2000; Pinker and Ullman, 2002b,a; McClelland and Patterson, 2002b,a). Connectionist networks have the advantage that they can account for graded, probabilistic phenomena. But they also have their share of disadvantages. One such a disadvantage is the merging of rules and representations. This might seem a step forward compared to the standard Von Neumann computer architecture that is the source of inspiration for symbolic models. However, rules and representations might have distinguishable neural substrates, as argued by Ullman (2001, 2004). According to Ullman, symbolic rules reside in a procedural memory system, and monomorphemic words and formatives in a declarative memory system. Evidence for such a division of labor for regular and irregular verbs comes from studies such as Jaeger et al. (1996) (positron emission topography) and Beretta et al. (2003) (functional magnetic resonance imaging). Interpretation of the reported differential activation of brain regions for regulars and irregulars is not straightforward, unfortunately. On the one hand, functional differentiation can take place in neural networks. Furthermore, present-to-past naming as used by Jaeger et al. (1996) is a task that, as discussed above, induces co-activation of inflectional variants that does not take place in normal speech. In addition, the experimental materials of regulars and irregulars are not appropriately controlled for semantic density and paradigm complexity (Baayen and Moscoso del Prado Martín, 2005). Nevertheless, the distinction between procedural and declarative knowledge is an important one and the available evidence reviewed by Ullman seems compelling.

Given the data reviewed in the preceding sections, it is clear that Ullman's straightforward traditional divide between regulars (processed by procedural memory) and irregulars (stored in declarative memory) must be too simplistic. Several modifications suggest themselves. Recall that the word frequency effect for very low-frequency complex words suggests that combinatorial probabilities may be at issue, for higher-frequency complex words probably in combination with phonological memory traces. It is conceivable that such combinatorial probabilities are evaluated in procedural memory as memories of previous assembly and decomposition allowing subsequent faster assembly and decomposition, whereas the phonological memory traces reside in declarative memory. Another possibility is that procedural memory is responsible for analogical generalization over lexical exemplars in declarative memory. Yet another alternative interpretation is that the weaker embodiment of regular verbs compared to irregulars goes hand in hand with greater multimodal computational demands across memory systems in the brain for conceptual interpretation, and that it is these additional costs that show up in brain imaging studies.

A second disadvantage is that the connectionist networks in common use are neurologically implausible. This is a key criticism made by Hawkins and Blakeslee (2004), a study that researches the consequences of the biological structure of the neocortex for intelligent computation (see also Miller, 2006). Interestingly, Hawkins and George (2006) provide an outline of a new implemented technology, Hierarchical Temporal Memory (HTM) that is designed to replicate the general structural and algorithmic properties of the neocortex. HTMs consist of a hierarchy of memory nodes. Each node is itself a network that learns causes from its child nodes and forms beliefs that it propagates to its parent nodes. Go- 
ing from low-level sensory nodes to higher-level nodes, the HTM performs as a classifier, coalescing a series of input patterns into a relatively stable output pattern. Conversely, a stable pattern at the top of the hierarchy can unfold into a complex temporal pattern at the bottom of the hierarchy.

Нтм memory is not designed specifically for language, but it promises to be a great tool for the computational modeling of the mental lexicon. Hтм as described by Hawkins and George (2006) is probably best seen as a computational model of declarative memory, albeit a memory system that is intrinsically predictive. In this sense, it is fundamentally different from a declarative memory conceived of as a static store of bits and bytes in the memory registers on a Von Neumann computer. Therefore, HTM bears the promise of being able to deal in a natural way with graded linguistic phenomena such as fine phonetic detail and the semi-morphology of phonaesthemes (Bergen, 2004). At the same time, rules and representations are not merged a priori. Nodes in the HTM memory can represent individuals and effectively function as symbols, albeit as symbols in a system with 'rules' that are inherently analogical and probabilistic in nature.

Нтм memory may also help resolve the problem of positional encoding that is rampant in analogical (Skousen, 1989) and machine learning (Daelemans and Van den Bosch, 2005) models as well as in connectionist networks. The alternative developed by Albright and Hayes (2003) is attractive in that it does not depend on positional encoding, but the price paid is a highly complex system of discrete rules. Since HTM memory is designed explicitly to match the spatial and temporal hierarchical structure of the real word, it may be able to detect structure in time without depending on predefined slots for the constituents of a linguistic unit.

Whereas the mathematics of formal languages has been a key source of inspiration for morphological theory and models of the mental lexicon, I expect new advances at the intersection of statistics, information science and the neurosciences such as Hierarchical Temporal Memory (and models using related techniques such as Dynamic Bayesian Networks) to constitute an important source of inspiration for research on the mental lexicon during the coming years.

As a consequence, not only the controversy between connectionist and symbolic approaches to the mental lexicon, but also the controversy between abstractionist and exemplar-based approaches may well be resolved in harmony. Any current exemplarbased machine learning algorithm must make use of smart economical storage, otherwise the system will grind to a halt when trying to survey all exemplars in its memory (see, e.g., the IG-tree technology used by TIMBL Daelemans and Van den Bosch 2005). On the other hand, the abovementioned frequency effects for fully regular complex words and the effects of inflectional and paradigmatic entropy bear witness to a remarkable sensitivity of lexical memory to very item-specific probabilities. In memory systems such as HTM, such item-specific probabilities are bound to be captured. On the other hand, such memory systems do not require as a matter of principle that all exemplars, such as the inflectional variants of a Spanish or Georgian verb, or all of a word's phonetic variants, are represented by individual nodes. Instead, HTM-like lexical memory systems promise to be fully compatible with the dynamic analogy-driven computation of morphologically complex words and their fine phonetic detail. 


\section{Acknowledgements}

I am indebted to Gonia Jarema, Gary Libben, Mark Pluymaekers, Mirjam Ernestus, Rachel Smith and Susanne Gahl for comments and discussion.

\section{References}

Albright, A., \& Hayes, B. (2003). Rules vs. analogy in English past tenses: A computational/experimental study. Cognition, 90, 119-161.

Alegre, M., \& Gordon, P. (1999). Frequency effects and the representational status of regular inflections. Journal of Memory and Language, 40, 41-61.

Aylett, M., Turk, A. (2004). The smooth signal redundancy hypothesis: a functional explanation for relationships between redundancy, prosodic prominence, and duration in spontaneous speech. Language and Speech, 47, 31-56.

Baayen, R., Feldman, L., \& Schreuder, R. (2006). Morphological influences on the recognition of monosyllabic monomorphemic words. Journal of Memory and Language, 53, 496-512.

Baayen, R. H., Dijkstra, T., \& Schreuder, R. (1997). Singulars and plurals in Dutch: Evidence for a parallel dual route model. Journal of Memory and Language, 36, 94117.

Baayen, R. H., \& Moscoso del Prado Martín, F. (2005). Semantic density and past-tense formation in three Germanic languages. Language, 81, 666-698.

Baayen, R. H., \& Schreuder, R. (2000). Towards a psycholinguistic computational model for morphological parsing. Philosophical Transactions of the Royal Society (Series A: Mathematical, Physical and Engineering Sciences), 358, 1-13.

Baayen, R. H., Schreuder, R., De Jong, N. H., \& Krott, A. (2002). Dutch inflection: the rules that prove the exception. In S. Nooteboom, F. Weerman, \& F. Wijnen (Eds.), Storage and Computation in the Language Faculty (pp. 61-92). Kluwer Academic Publishers, Dordrecht.

Bard, E., Anderson, A., Sotillo, C., Aylett, M., Doherty-Sneddon, G., \& Newlands, A. (2000). Controlling the Intelligibility of Referring Expressions in Dialogue. Journal of Memory and Language, 42, 1-22.

Barsalou, L. W. (2003). Situated simulation in the human conceptual system. Language and Cognitive Processes, 18, 513-562.

Bell, A., Jurafsky, D., Fosler-Lussier, E., Girand, C., Gregory, M., \& Gildea, D. (2003). Effects of disfluencies, predictability, and utterance position on word form variation in English conversation. Journal of the Acoustical Society of America, 113, 1001-1024.

Beretta, A., Campbell, C., Carr, T., Huang, J., Schmitt, L. M., Christianson, K., \& Cao, Y. (2003). An ER-fMRI investigation of morphological inflection in German reveals that the brain makes a distinction between regular and irregular forms. Brain and Language, 85, 67-92.

Bergen, B. K. (2004). The psychological reality of phonaesthemes. Language, 80, 290-311. 
Bien, H., Levelt, W., \& Baayen, R. H. (2005). Frequency effects in compound production. Proceedings of the National Academy of Sciences of the USA, 102, 17876-17881.

Bien, H., Levelt, W., \& Baayen, R. H. (2006). Frequency effects in the production of derivations and inflections. Manuscript in preparation, Max Planck Institute for Psycholinguistics, Nijmegen.

Bloch, B. (1947). English verb inflection. Language, 23, 399-418.

Bloomfield, L. (1933). Language. Allen and Unwin, London.

Bod, R. (2006). Exemplar-based syntax: How to get productivity from examples. The Linguistic Review, 23, in press.

Bybee, J. L., \& Moder, C. L. (1983). Morphological classes as natural categories. Language 59, 251-270.

Bybee, J. L., \& Slobin, D. I. (1982). Rules and schemas in the development and use of the english past tense. Language, 58, 265-289.

Cholin, J., Schiller, N. O., \& Levelt, W. J. M. (2004). The preparation of syllables in speech production. Journal of Memory and Language, 20, 47-61.

Chomsky, N., \& Halle, M. (1968). The sound pattern of English. Harper and Row, New York.

Daelemans, W., \& Van den Bosch, A. (2005). Memory-based language processing. Cambridge University Press, Cambridge.

De Vaan, L., Schreuder, R., \& Baayen, R. H. (2007). Regular morphologically complex neologisms leave detectable traces in the mental lexicon. The Mental Lexicon, 2, in press.

Dell, G., Chang, F., \& Griffin, Z. (1999). Connectionist Models of Language Production: Lexical Access and Grammatical Encoding. Cognitive Science, 23, 517-542.

Ernestus, M. (2000). Voice assimilation and segment reduction in casual Dutch. LOT, Utrecht.

Ernestus, M., \& Baayen, R. H. (2006)a. The functionality of incomplete neutralization in Dutch. The case of past-tense formation. Laboratory Phonology, 8, 27-49.

Ernestus, M., \& Baayen, R. H. (2006)b. Paradigmatic effects in auditory word recognition: The case of alternating voice in Dutch. Language and Cognitive Processes, in press.

Ernestus, M., \& Baayen, R. H. (2003). Predicting the unpredictable: Interpreting neutralized segments in Dutch. Language, 79, 5-38.

Ernestus, M., Lahey, M., Verhees, F., \& Baayen, R. H. (2006). Lexical frequency and voice assimilation. Journal of the Acoustical Society of America, 120, 1040-1051.

Feldman, J. (Ed.) (2006). From molecule to metaphor. A neural theory of language. The MIT Press, Cambridge, MA.

Fowler, C. (1988). Differential shortening of repeated content words produced in various communicative contexts. Language and Speech, 31, 307-317.

Fowler, C., \& Housum, J. (1987). Talkers' Signalling of "New" and "Old" Words in Speech and Listeners' Perception and Use of the Distinction. Journal of Memory and Language, 26, 489-504.

Gahl, S. (2006). Is frequency a property of phonological forms? Evidence from spontaneous speech. Paper presented at the 19th Annual CUNY Conference on Human Sentence Processing, New York City. 
Gahl, S., \& Garnsey, S. (2004). Knowledge of grammar, knowledge of usage: Syntactic probabilities affect pronunciation variation. Language, 80, 748-774.

Gahl, S., \& Garnsey, S. (2006). Knowledge of grammar includes knowledge of syntactic probabilities. Language, 82, 405-410.

Gregory, M., Raymond, W., Bell, A., Fosler-Lussier, E., \& Jurafsky, D. (1999). The effects of collocational strength and contextual predictability in lexical production. CLS, 35, 151-166.

Halle, M., \& Marantz, A. (1993). Distributed morphology and the pieces of inflection. In K. Hale \& S. J. Keyser (Eds.), The View from Building 20: Essays in Linguistics in Honor of Sylvain Bromberger (pp. 111-176). Vol. 24 of Current Studies in Linguistics. MIT Press, Cambridge, Mass.

Hawkins, J., \& Blakeslee, S. (2004). On intelligence. Henry Holt and Company, New York.

Hawkins, J., \& George, D. (2006). Hierarchical temporal memory. Concepts, theory and terminology. Numenta Technology, http://www.numenta.com/technology.php.

Hawkins, S. (2003). Roles and representations of systematic fine phonetic detail in speech understanding. Journal of Phonetics, 31, 373-405.

Hawkins, S., \& Warren, P. (1994). Phonetic influences on the intelligibility of conversational speech. Journal of Phonetics, 22, 493-511.

Hay, J. (2001). Lexical frequency in morphology: Is everything relative? Linguistics, 39, 1041-1070.

Jaeger, J. J., Lockwood, A. H., Kemmerrer, D. L., Van Valin, R. D., \& Murphy, B. W. (1996). A positron emission tomographic study of regular and irregular verb morphology in English. Language, 72, 451-497.

Joanisse, M. F., \& Seidenberg, M. S. (1999). Impairments in verb morphology after brain injury: a connectionist model. Proceedings of the National Academy of Sciences, 96, $7592-7597$.

Jurafsky, D., Bell, A., Gregory, M., \& Raymond, W. (2001). Probabilistic relations between words: Evidence from reduction in lexical production. In J. Bybee \& P. Hopper (Eds.), Frequency and the emergence of linguistic structure (pp. 229-254). Benjamins, Amsterdam.

Jurafsky, D., Bell, A., \& Gyrand, C. (2002). The role of the lemma in form variation. In C. Gussenhoven \& N. Warner (Eds.), Papers in Laboratory Phonology VII (pp. 1-34). Mouton de Gruyter, Berlin/New York.

Keating, P. A. (2006). Phonetic encoding of prosodic structure. In J. Harrington \& M. Tabain (Eds.), Speech production: Models, phonetic processes, and techniques (pp. 167186). Psychology Press, New York and Hove.

Kemps, R., Ernestus, M., Schreuder, R., \& Baayen, R. H. (2005)a. Prosodic cues for morphological complexity: The case of Dutch noun plurals. Memory and Cognition, 33, 430-446.

Kemps, R., Wurm, L., Ernestus, M., Schreuder, R., \& Baayen, R. H. (2005)b. Prosodic cues for morphological complexity in Dutch and English. Language and Cognitive Processes, 20, 43-73.

Keune, K., Ernestus, M., Van Hout, R., \& Baayen, R. H. (2005). Social, geographical, and register variation in Dutch: From written 'mogelijk' to spoken 'mok'. Corpus Linguistics and Linguistic Theory, 1, 183-223. 
Kostić, A., Marković, T., \& Baucal, A. (2003). Inflectional morphology and word meaning: Orthogonal or co-implicative domains? In: R. H. Baayen \& R. Schreuder (Eds.), Morphological Structure in Language Processing (pp. 1-44). Mouton de Gruyter, Berlin.

Krott, A., Baayen, R. H., \& Schreuder, R. (2001). Analogy in morphology: modeling the choice of linking morphemes in Dutch. Linguistics, 39, 51-93.

Krott, A., Hagoort, P., Baayen, R. H. (2004). Sublexical units and supralexical combinatorics in the processing of interfixed Dutch compounds. Language and Cognitive Processes, 19, 453-471.

Kuperman, V., Pluymaekers, M., Ernestus, M., \& Baayen, R. H. (2006). Morphological predictability and acoustic salience of interfixes in Dutch compounds. Submitted.

Lehiste, I. (1972). The timing of utterances and linguistic boundaries. JASA, 51, 20182024.

Levelt, W. J. M., Roelofs, A., \& Meyer, A. S. (1999). A theory of lexical access in speech production. Behavioral and Brain Sciences, 22, 1-38.

Lieber, R. (1980). On the organization of the lexicon. Ph.D. thesis, MIT, Cambridge.

Lindblom, B. (1990). Explaining phonetic variation: A sketch of the H\&H theory. In W. Hardcastle \& A. Marchal (Eds.), Speech production and speech modeling (pp. 403-440). Kluwer, Dordrecht.

MacWhinney, B., \& Leinbach, J. (1991). Implementations are not conceptualizations: revising the verb learning model. Cognition, 40, 121-157.

Marslen-Wilson, W. D. (1996). Function and process in spoken word recognition. In: Attention and performance: Control of language processes. Vol. X. Lawrence Erlbaum Associates, Hillsdale, NJ, pp. 125-150.

Marslen-Wilson, W. D., \& Welsh, A. (1978). Processing interactions and lexical access during word recognition in continuous speech. Cognitive Psychology, 10, 29-63.

Matthews, P. H. (1974). Morphology. An Introduction to the Theory of Word Structure. Cambridge University Press, London.

McCarthy, J. J., \& Prince, A. (1993). Generalized alignment. In G. E. Booij \& J. van Marle (Eds.), Yearbook of Morphology (pp. 79-154). Kluwer Academic Publishers, Dordrecht.

McClelland, J. L., \& Patterson, K. (2002)a. Rules or connections in past-tense inflections: what does the evidence rule out. Trends in the Cognitive Sciences, 6, 465-472.

McClelland, J. L., \& Patterson, K. (2002)b. 'words or rules' cannot exploit the regularity in exceptions: Reply to Pinker and Ullman. Trends in the Cognitive Sciences, 6, 464465.

Miller, G. (2006). An enterprising approach to brain science. Science, 324, 76-77.

Moscoso del Prado Martín, F., Bertram, R., Häikiö, T., Schreuder, R., \& Baayen, R. H. (2004)a. Morphological family size in a morphologically rich language: The case of Finnish compared to Dutch and Hebrew. Journal of Experimental Psychology: Learning, Memory and Cognition, 30, 1271-1278.

Moscoso del Prado Martín, F., Kostić, A., \& Baayen, R. H. (2004)b. Putting the bits together: An information theoretical perspective on morphological processing. Cognition, 94, 1-18.

Munson, B., \& Solomon, N. P. (2004). The effects of phonological neighborhood density on vowel articulation. Journal of Speech, Language, and Hearing Research, 47, 1048-1058. 
Oostdijk, N. (2002). The design of the Spoken Dutch Corpus. In P. Peters, P. Collins \& A. Smith (Eds.), New Frontiers of Corpus Research (pp. 105-112). Rodopi, Amsterdam.

Oostdijk, N., Goedertier, W., Van Eynde, F., Boves, L., Martens, J., Moortgat, M., \& Baayen, R. H. (2002). Experiences from the Spoken Dutch Corpus Project. In M. Gonz ez Rodriguez \& C. Paz Su ez Araujo (Eds.), Proceedings of the third International Conference on Language Resources and Evaluation, ELRA, pp. 340-347.

Patterson, K., Lambon Ralph, M., Hodges, J., \& McClelland, J. (2001)a. Deficits in irregular past-tense verb morphology associated with degraded semantic knowledge. Neuropsychologia, 39, 709-724.

Patterson, K., Lambon Ralph, M. A., Hodges, J. R., \& McClelland, J. L. (2001)b. Deficits in irregular past-tense verb morphology associated with degraded semantic knowledge. Neuropsycologia, 39, 709-724.

Pinker, S. (1991). Rules of language. Science, 153, 530-535.

Pinker, S. (1997). Words and rules in the human brain. Nature, 387, 547-548.

Pinker, S. (1999). Words and Rules: The Ingredients of Language. Weidenfeld and Nicolson, London.

Pinker, S., \& Prince, A. (1988). On language and connectionism. Cognition, 28, 73-193.

Pinker, S., \& Prince, A. (1994). Regular and irregular morphology and the psychological status of rules of grammar. In S. Lima, R. Corrigan \& G. Iverson (Eds.), The Reality of Linguistic Rules (pp. 353-388). John Benjamins, Amsterdam.

Pinker, S., \& Ullman, M. (2002)a. Combination and structure, not gradedness, is the issue. Trends in Cognitive Sciences, 6, 472-474.

Pinker, S., \& Ullman, M. (2002)b. The past and future of the past tense. Trends in the Cognitive Sciences, 6, 456-462.

Plug, L. (2005). From words to actions: The phonetics of 'eigenlijk' in two communicative contexts. Phonetica, 62, 131-145.

Plunkett, K., \& Marchman, V. (1991). U-shaped learning and frequency effects in a multilayered perceptron: implications for child language acquisition. Cognition, 38, 1-60.

Pluymaekers, M., Ernestus, M., \& Baayen, R. H. (2005)a. Articulatory planning is continuous and sensitive to informational redundancy. Phonetica, 62, 146-159.

Pluymaekers, M., Ernestus, M., Baayen, R. H. (2005)b. Frequency and acoustic length: the case of derivational affixes in Dutch. Journal of the Acoustical Society of America, 118, 2561-2569.

Pluymaekers, M., Ernestus, M., \& Baayen, R. H. (2006). Effects of word frequency on articulatory durations. Submitted.

Roelofs, A. (1996). Serial order in planning the production of successive morphemes of a word. Journal of Memory and Language, 35, 854-876.

Roelofs, A. (1997)a. Morpheme frequency in speech production: Testing WEAVER. In G. E. Booij \& J. van Marle (Eds.), Yearbook of Morphology 1996 (pp. 135-154). Kluwer, Dordrecht.

Roelofs, A. (1997)b. The WEAVER model of word-form encoding in speech production. Cognition, 64, 249-284. 
Rumelhart, D. E., \& McClelland, J. L. (1986). On learning the past tenses of English verbs. In J. L. McClelland \& D. E. Rumelhart (Eds.), Parallel Distributed Processing. Explorations in the Microstructure of Cognition. Vol. 2: Psychological and Biological Models. (pp. 216-271). The MIT Press, Cambridge, Mass.

Scarborough, R. A. (2004). Coarticulation and the structure of the lexicon. UCLA dissertation.

Seidenberg, M. S., \& Gonnerman, L. M. (2000). Explaining derivational morphology as the convergence of codes. Trends in Cognitive Sciences, 4, 353-361.

Selkirk, E. (1984). Phonology and Syntax. The MIT Press, Cambridge.

Sereno, J., \& Jongman, A. (1997). Processing of English inflectional morphology. Memory and Cognition, 25, 425-437.

Sevald, A. C., \& Dell, G. S. (1994). The sequential cuing effect in speech production. Cognition, 53, 91-127.

Sevald, A. C., Dell, G. S., \& Cole, J. S. (1995). Syllable Structure in Speech Production: Are Syllables Chunks or Schemas? Journal of Memory and Language, 34, 807-820.

Shannon, C. E., \& Weaver, W. (1949). The Mathematical Theory of Communication. The University of Illinois Press, Urbana.

Skousen, R. (1989). Analogical Modeling of Language. Kluwer, Dordrecht.

Stemberger, J. P. (2004). Phonological priming and irregular past. Journal of Memory and Language, 50, 82-95.

Stemberger, J. P., \& Middleton, C. (2003). Vowel dominance and morphological processing. Language and Cognitive Processes, 18, 369-404.

Tabak, W., Schreuder, R., Baayen, R. H. (2005)a. Lexical statistics and lexical processing: semantic density, information complexity, sex, and irregularity in Dutch. In S. Kepser \& M. Reis (Eds.), Linguistic Evidence - Empirical, Theoretical, and Computational Perspectives (pp. 529-555). Mouton de Gruyter, Berlin.

Tabak, W., Schreuder, R., \& Baayen, R. H. (2005)b. The processing of regular and irregular verbs. In Proceedings of the Interdisciplinary Workshop on the Identification and Representation of Verb Features and Verb Classes, Saarbrücken, pp. 121-126.

Tabak, W., Schreuder, R., \& Baayen, R. H. (2006). Nonderivational inflection. Manuscript, Max Planck Institute for Psycholinguistics.

Taft, M. (1979). Recognition of affixed words and the word frequency effect. Memory and Cognition, 7, 263-272.

Trón, V. (2006). Corpus evidence for a priming account of durational reduction. Paper presented at the 2nd Annual Edinburgh Psycholinguistics postgraduate conference, 2006.

Tyler, L., Stamatakis, E., Jones, R., Bright, P., Acres, K., \& Marslen-Wilson, W. (2004). Deficits for semantics and the irregular past tense: A causal relationship? Journal of Cognitive Neuroscience, 16, 1159-1172.

Ullman, M. (2001). The declarative/procedural model of lexicon and grammar. Journal of Psycholinguistic Research, 30, 37-69.

Ullman, M. (2004). Contributionss of memory circuits to language: the declarative/procedural model. Cognition, 92, 231-270.

Van Buren, H., Tabak, W., Carreiras, M., \& Baayen, R. H. (2006). Morphological effects in picture naming of spanish verbs by L1 and L2 speakers. Manuscript in preparation. 
Van Haeringen, C. B. (1940). De taaie levenskracht van het sterke werkwoord. De Nieuwe Taalgids, 34, 241-255.

Van Son, R., \& Pols, L. (2003). Information Structure and Efficiency in Speech Production. Proceedings of Eurospeech-2003. Geneva, Switzerland, 769-772.

Van Son, R., \& Van Santen, J. (2005). Duration and spectral balance of intervocalic consonants: A case for efficient communication. Speech Communication, 47, 100-123.

Vitevitch, M. S. (2002). The influence of phonological similarity neighborhoods on speech production. Journal of Experimental Psychology: Learning, Memory and Cognition, 28, $735-747$.

Vitevitch, M. S., \& Stamer, M. K. (2006). The curious case of competition in Spanish speech production. Language and cognitive processes, 21, 760-770.

Wright, R. (2004). Factors of lexical competition in vowel articulation. In J. Local \& R. Ogden (Eds.), Papers in Laboratory Phonology 6 (pp. 75-87). Cambridge University Press, Cambridge.

Wurm, L. H., \& Baayen, R. H. (2006). Sufrace frequency effects below the threshold: Comparing types, tasks, and modalities. Submitted. 